\title{
Simultaneous infection with two types of intestinal microsporidia in a patient with AIDS
}

\author{
C Blanshard, W S Hollister, C S Peacock, D G Tovey, D S Ellis, E U Canning, B G Gazzard
}

\begin{abstract}
We report the first case of a non-Enterocytozoon bieneusi microsporidial infection in the small intestine of a European AIDS patient with diarrhoea. It is also the first case in which a double infection with two different types of microsporidia has been encountered.
\end{abstract}

Intestinal infection with microsporidia has been described in association with diarrhoea in patients with AIDS from Europe,' the United States,' and Africa. ${ }^{3}$ All infections have been with Enterocytozoon bieneusi with the exception of one, ${ }^{4}$ and in this case the species was not identified.

AIDS Unit, Westminster Hospital, London C Blanshard B G Gazzard

London School uf Hygiene and Tropical Medicine, London C S Peacock

D G Tovey

D S Ellis

Department of Biology, Imperial College of

Science, Technology and Medicine, London W S Hollister E U Canning

Correspondence to: Dr Gazzard, AIDS Unit, Westminster Hospital, Horseferry Road, London SW1P 2AP.

Accepted for publication 10 June 1991

\section{Case history}

A 45 year old homosexual man of Italian origin presented with a nine week history of profuse diarrhoea (five to 15 liquid non-bloody stools daily) accompanied by colicky lower abdominal pain, urgency of defecation, and weight loss of 2 kg. He had been known to be HIV-seropositive since 1985 and had previously had two episodes of cytomegalovirus colitis, miliary tuberculosis, and oesophageal candida. He was resident in England and had not travelled abroad before the onset of symptoms.

Physical examination and sigmoidoscopy were normal. Light microscopy of three rectal biopsy specimens and microbiological analysis of six stool specimens showed no pathogens. Multiple pinch biopsy specimens were obtained from the distal duodenum at fibreoptic endoscopy and a

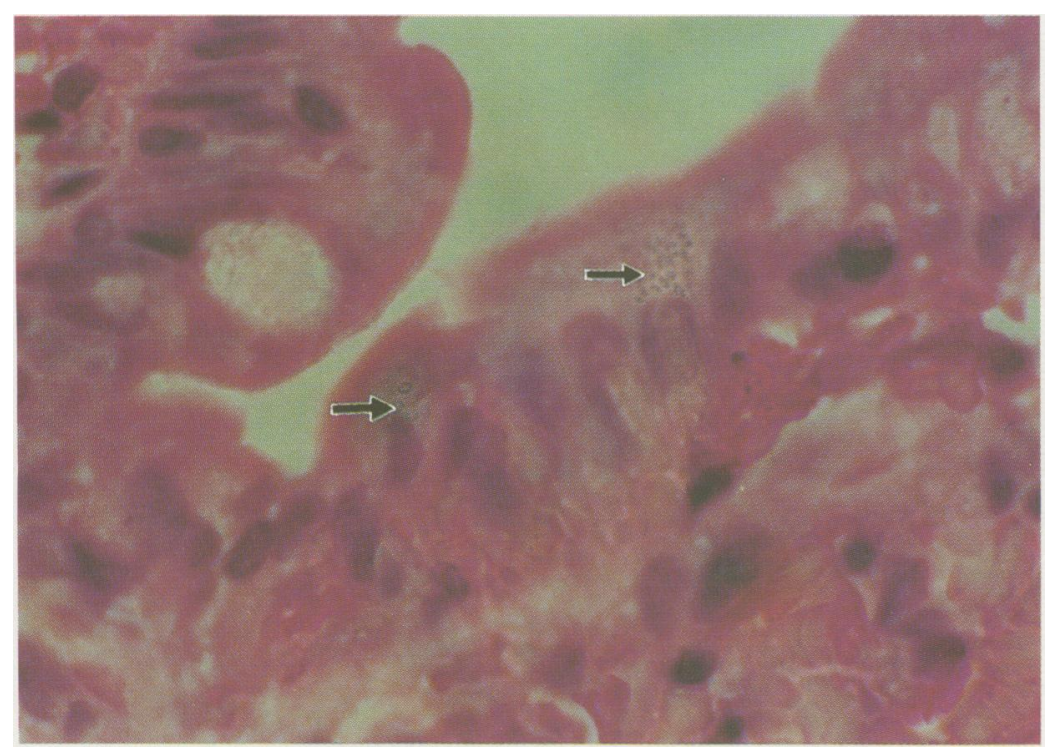

Figure 1: Spores of the two different types of microsporidia (arrowed) in the enterocytes of this patient, the larger about $2 \cdot 5 \mu \mathrm{m}$ and the smaller $1 \mu \mathrm{m}$. (Haematoxylin and eosin, original magnification approximately $\times 1000$.)

Watson capsule was passed into the upper jejunum where a further biopsy specimen was obtained. Material was processed for light and electron microscopy. A single rectal biopsy taken $10 \mathrm{~cm}$ from the anal margin was also processed for electron microscopy.

Three weeks after presentation the patient died suddenly of a cerebral haemorrhage. Unfortunately, a necropsy could not be performed.

\section{Histological methods}

For light microscopy, impression smears were made, dried, and fixed in absolute methanol for 30 seconds and then stained in $10 \%$ Giemsa for 30 minutes. Specimens were also fixed for at least three hours in $10 \%$ formol saline, dehydrated through graded ethanol solutions, cleared in Citroclear, and embedded in paraffin wax or glycomethacrylate resin. Paraffin sections 2-5 $\mu \mathrm{m}$ thick and resin sections $1 \mu \mathrm{m}$ thick were stained with Giemsa or Erlich's haematoxylin and eosin.

For electron microscopy, specimens were fixed in $3 \%$ glutaraldehyde in $0.1 \mathrm{~mol} / 1$ cacodylate buffer ( $\mathrm{pH} 7 \cdot 3$ ), post fixed in $1 \%$ osmium tetroxide, dehydrated through graded methanol solutions, block stained in uranyl acetate, impregnated via propylene oxide, and embedded in Taab resin. Sections $70 \mathrm{~nm}$ thick were stained with lead citrate and examined using a JEOL 100 CX microscope.

\section{Results}

At light microscopy, the smears and sections showed numerous developmental stages and spores of Enterocytozoon bieneusi, the identifying features of which have been previously described. ${ }^{56}$ There were also some bodies which had the characteristic features of microsporidian spores but were much larger than those of $E$ bieneusi, measuring 2-2.5 $\mu \mathrm{m}$ long, and were broadly ellipsoid in shape (Figs 1 and 2). They lay in the same position in the enterocytes as the stages of $E$ bieneusi - that is, between the nucleus and the microvillous border - and up to 60 of these spores could be seen in each infected cell. The nuclear complement of the spores could not be determined. The sections of duodenal and jejunal biopsy material also showed severe atrophy of villi with vacuolation of the enterocytes and an infiltrate of chronic inflammatory cells. Far fewer enterocytes were infected with the new organism than with $E$ bieneusi.

Electron microscopy confirmed heavy infection of the biopsy tissue with $E$ bieneusi. Two features were seen which have not previously been described. Firstly, there were interdigitat- 


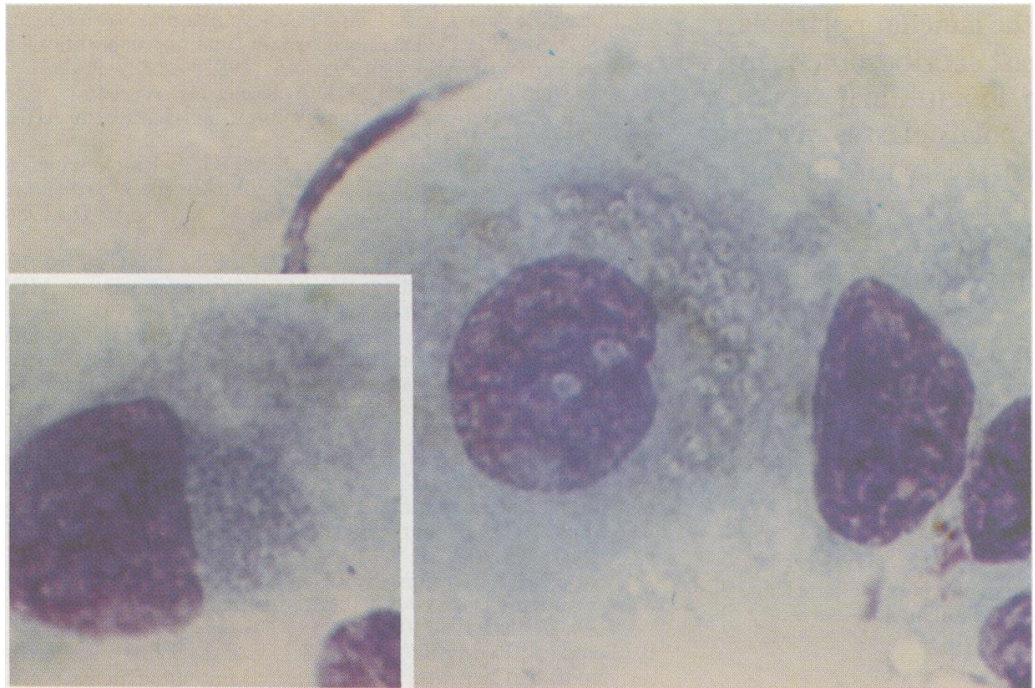

Figure 2: Detail of a duodenal smear showing an enterocyte filled with the large, ovoid spores of the new microsporidia. Another cell contains numerous spores of Enterocytozoon bieneusi (insert). (Giemsa, original magnification $\times 2000$ approximately.)

ing interfaces between meronts in multiply infected enterocytes (Fig 3). Secondly, in the spores, the ribosomes associated with the lamellar polaroplast, were organised as transverse rows of about six ribosomes across the lamellae and longitudinal rows following the contours of the lamellae (Fig 4)

In the rectal biopsy specimen, the enterocytes contained degenerate ovoid bodies of the same size and occupying the same position in the cell as microsporidia (Fig 5).

\section{Discussion}

Six different species of microsporidia have been reported to infect immunocompromised patients, invading the intestine,${ }^{47}$ the cornea, ${ }^{8}$ the peritoneum, ${ }^{9}$ the liver, ${ }^{10}$ and skeletal muscle, ${ }^{11}$ but so far only $E$ bieneusi has been positively identified in the small intestine in association with diarrhoea. This case shows that there is another type of microsporidia, distinguishable from $E$ bieneusi at light microscopy, that is capable of infecting the small intestine in AIDS patients. It is also the first case in which two

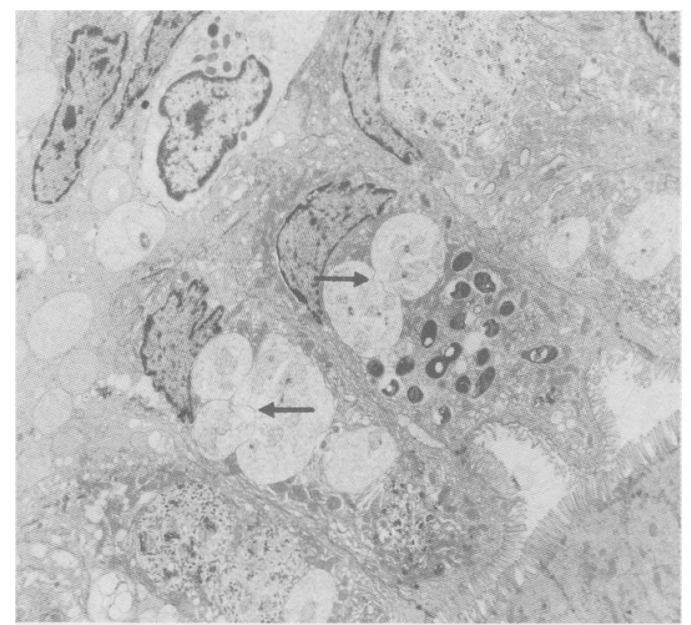

Figure 3: Interdigitating meronts (arrowed). Note the heavy infection. (Original magnification $\times 4000$.)

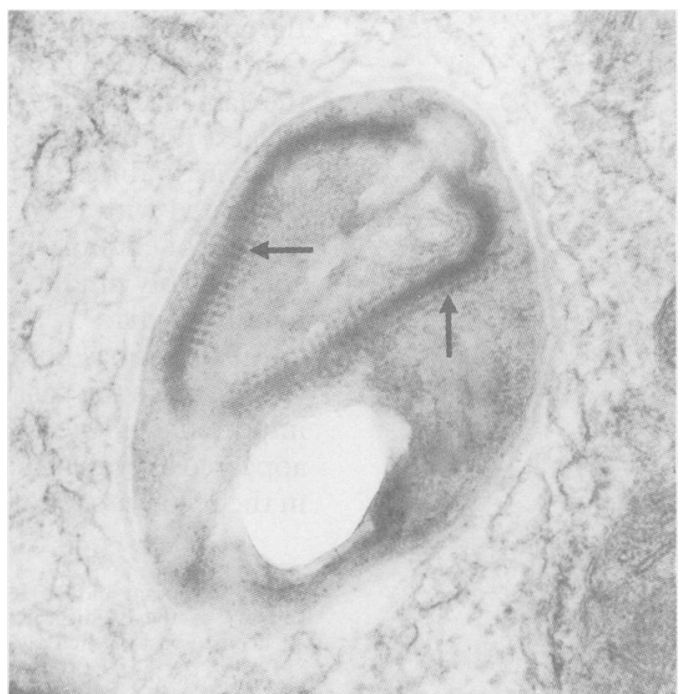

Figure 4: Spore showing the arrangement of the rows of ribosomes across the lamellae (arrowed). (Original magnification $\times 80000$.

different types of microsporidia have been found in the same patient.

Unfortunately, because of their sparse distribution, it was not possible to study the ultrastructural features of the second parasite under the electron microscope and therefore identify the species, or determine whether it is the same as that described by Orenstein et $_{\text {al }} .^{+}$

The clinical features and pathological changes in the small intestine biopsy specimens in this case were indistinguishable from those we have seen in infection with $E$ bieneusi alone, and therefore the importance of the second parasite cannot be determined.

The electron microscopic features of $E$ bieneusi seen in this case were unusual. Cali and Owen ${ }^{12}$ reported that multiple proliferative phases (meronts) of $E$ bieneusi abutted against one another in enterocytes but division of meronts was not observed. We have also observed multiple meronts in cells without signs of cell division by constriction, which suggests that if division of the meronts occurs at all it must either occur very rapidly or involve the formation of the intervening membranes internally from endoplasmic reticulum. The interdigitating interfaces which we observed would support the latter hypothesis. Cali and Owen ${ }^{12}$ also reported the presence of ribosomes arranged as two rows on

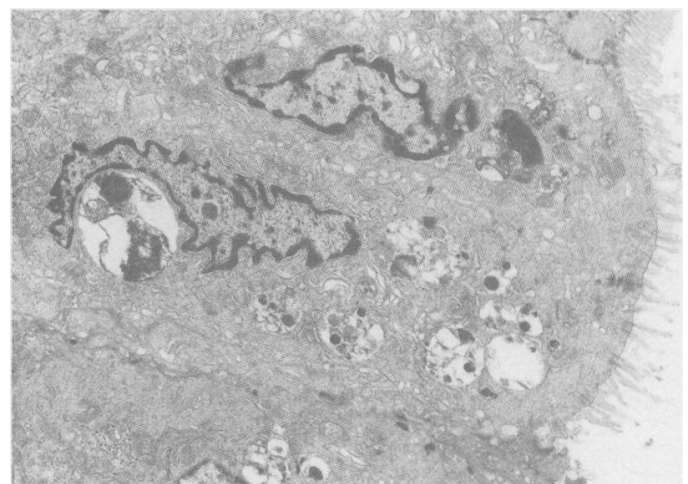

Figure 5: The degenerating bodies found in rectal enterocytes. (Original magnification $\times 10000$.) 
the outermost lamella of the lamellar polaroplast. Our observations of at least six ribosomes across the lamellae, as seen in longitudinal sections, suggest that the lamellar polaroplast is made up of at least three flattened sacs with ribosomes associated with both surfaces of each sac, in the manner of endoplasmic reticulum. It is unusual, and possibly unique, to find this arrangement in microsporidia.

$E$ bieneusi has not been found in rectal biopsy specimens in the past and we are uncertain of the importance of the widespread presence of what appeared to be degenerate forms of microsporidia in the rectal tissues of this patient.

Professor Canning and Dr Hollister would like to acknowledge the support of the Medical Research Council and currently the Wellcome Trust for their part in this work.

1 Curry A, McWilliam LJ, Haboubi NY, Mandal BK. Microsporidiosis in a British patient with AIDS. $\mathcal{F}$ Clin Pathol 1988; 41: 477-8.

2 Orenstein JM, Chang J, Steinberg W, Smith PD, Rotterdam H, Kotler DP. Intestinal microsporidiosis as a cause of diarrhea in HIV-infected patients: a report of 20 cases. Hum Pathol 1990; 21: 475-81.
3 Lucas SB, Papadaki L, Conlon C, Sewankambo N, Goodgame $R$, Serwadda D. Diagnosis of intestinal microsporidiosis in patients with AIDS. F Clin Pathol 1989; 42: 885-90.

4 Orenstein JM, Tenner M, Cali A, Kotler DP. A second species of microsporidia that causes intestinal disease in AIDS. Gastroenterology 1990; 98: A467.

5 Rijpstra AC, Canning EU, Van Ketel RJ, Eeftinck Schattenkerk JKM, Laarman JJ. Use of light microscopy to diagnose small intestinal microsporidiosis in AIDS. $\mathcal{F}$ Infect Dis 1988; 157: 827-31.

6 Peacock CS, Blanshard C, Tovey DG, Ellis DS, Gazzard BG. The histological diagnosis of microsporidiosis in AIDS The histological diagnosis of microsporid

7 Desportes I, Le Charpentier Y, Galian A, Bernard F, CochardPriollet B, Laverne A, et al. Occurrence of a new microsporidian Enterocytozoon bieneusi n.g., n.sp., in cytes of a human patient with AIDS. 7 Protozool 1985; 32: $250-4$.

8 Didier ES, Didier PJ, Friedberg DN, Stenson SM, Orenstein $\mathrm{JM}$, Yee RW, et al. Isolation and characterisation of a new human microsporidian, Encephalitozoon hellem n.sp. from three AIDS patients with keratoconjunctivitis. $\mathcal{F}$ Infect Dis 1991; 193: 617-21.

9 Zender HO, Arrigoni E, Eckert E, Kapanci Y. A case of Encephalitozoon cunicli Peritonitis in a patient with AIDS. Encephalitozoon cunicli Peritonitis

10 Terada S, Reddy KR, Jeffers LJ, Cali A, Schiff ER. Microsporidian hepatitis in the acquired immunodeficiency syn-

11 Ledford DK, Overman MD, Gonzalvo A, Cali A, Mester W, Lockey RF. Microsporidiosis myositis in a patient with the acquired immune deficiency syndrome. Ann Intern Med 1985; 102: 628-30.

12 Cali A, Owen RL. Intracellular development of Enterocytozoon, a unique microsporidian found in the intestine of AIDS patients. F Protozool 1990; 37: 145-55. 